\title{
Beyond IPCC, Research for Paris 2015 and Beyond
}

\author{
Thomas Sterner ${ }^{1,2}$
}

Published online: 29 September 2015

C) Springer Science+Business Media Dordrecht 2015

The Climate conference in Paris December 2015 is described as "last chance" or "5 to twelve" but in the climate arena there is a risk that we have over-utilized the doomsday vocabulary already in the run-up to Copenhagen, 2009 the better part of a decade ago. For those who have worked on climate issues for several decades it poses a special challenge to calibrate language. Words like "immediate" need careful explanation. Think of a super tanker with so much inertia that it takes a full hour to stop in an emergency - and in our case it is not an hour but decades - damage is probably quite gradual and yet there is literally no time to delay.

Activists feel that we have to use every opportunity to further climate change policy because not much has been achieved to date and December 2015 does represent a special opportunity but clearly it is an illusion that any one particular meeting will cut the Gordian knot and result in a full international treaty with appropriate policies for all the countries of the world. The UNFCCC has yearly conferences of the parties (COP) but the expectations have not been this high since Copenhagen which was later described as a big failure. Politicians are keen to avoid a repeat and so expectations have been lowered. We are no longer seeking a grand agreement but a set of "Intended, Nationally Determined Contributions", INDCs. Both the qualifiers "intended" and "nationally determined" raise issues related to the design of a treaty intended to provide a global public good. Normally we need to make sure that commitments are verifiable, controllable, add up to a sufficient aggregate goal and that there are incentives to deliver on the commitment.

The Kyoto Protocol has been severely criticized-not least in the USA. American observers have pointed at the asymmetry created by requiring virtually nothing of large and growing emitters such as China. This interpretation of the Rio principle of "common but differentiated responsibilities" has effectively made it impossible to pass any effective

Special thanks to Yonas Alem, Dallas Burtraw, Cameron Hepburn, Somanathan, Amie Svärd and Nicolas Treich for very useful comments to an earlier draft.

Thomas Sterner

thomas.sterner@economics.gu.se

1 Gothenburg University, Göteborg, Sweden

2 Collège de France, Paris, France 
climate legislation in US Congress. In the US, it came as something of a chock that China had higher emissions than the US (in absolute terms). Since China is already seen as a major competitor in industrial and even global power terms as well as being a major creditor to the US, it became politically impossible for the US to undertake major restrictions if China was unrestricted. On the other hand, the Chinese population is more than four times larger and from their perspective this means that the per capita emissions are still severely skewed in the sense that the US (and other rich industrialized nations) are still using up a disproportionate share of what is effectively a global commons (the ability of the atmosphere to assimilate carbon dioxide and other climate gasses). When considering the accumulated emissions from the past this disparity is even more salient. The perspective of India is even more striking since per capita emissions are very much lower than in China and less than a tenth of the US values. An international scheme with tradable permits that were allocated on some form of per capita basis would give an enormous rent to India. (The US would be one of the major buyers creating very large financial transfers from the US and other rich countries with high emissions to India and other low emitters. Countries like China with emissions per capita closer to the average would be less affected).

Negotiations on the second period of the Kyoto Protocol stranded because major economies like the USA and China were unwilling or unable to commit to legally binding quantitative restrictions. This is probably due largely to the fact that opinions on the details of what would be fair or reasonable allocations are so far apart. Many observers consider the Kyoto structure fatally flawed for various reasons but chiefly because of insufficient attention to the interests of the most powerful nations and no demands on the non-annex 1 countries, as well as insufficient incentives to make parties want to stay in the agreement. Negotiations were held in Lima in 2014 to agree on a post-Kyoto framework that would entice all major polluters to join and this is how the "pledge and review" approach was reborn (it was the original approach but became foreshadowed during the period when negotiations focused on binding commitments). The concern now is that acceptability has been acquired at the price of a weak architecture: Public goods are not normally provided (in sufficient amounts at least) by voluntary mechanisms. Hence, more is needed than intended, nationally determined, contributions before we can rest assured that total emissions will be sufficiently low to meet any given target in terms of carbon concentrations in the atmosphere and even more before we can start to discuss enforcement and verification issues; see Green et al. (2014) for more discussion on decentralized architecture and its connection to instrument choice and see Boyd et al. (2015) for an analysis showing that the INDCs published to date are far from sufficient to meet a $2{ }^{\circ} \mathrm{C}$ target.

It is also clear that treaty design may be intricately tied to the other big and controversial issue of climate policy: the choice of policy instruments at local and national levels may be an important factor that can shape the preconditions for international agreements. Recently, a number of prominent researchers have suggested, partly in response to the negotiating difficulties, that the World urgently needs a (minimum) carbon price. The exact instrument proposed varies between authors. Some argue for actual taxes (Nordhaus 2013, 2015; Weitzman 2014) while others argue for a permit scheme or a tax as long as it delivers a uniform price and addresses issues of distribution and incentives (Gollier and Tirole 2015). Both Weitzman and Nordhaus emphasize that the actual process of treaty negotiation itself may be easier if the subject of the negotiation is not framed in terms of quantities (which inevitably leads negotiators to think in terms of zero-sum games) but instead in terms of minimum tax or price levels. Weitzman focuses on both the incentive and informational aspects-it is simply much easier to discuss one price than a whole set of $N$ country reductions. Nordhaus proposes the formation of "climate clubs" that require members to have a minimum carbon 
price and potentially use trade or other sanctions to entice non-members to join. A hybrid approach (between price and quantity instruments) has been adopted in three North American trading programs that include a reserve price in their auctions of emissions allowances, which serve as a price floor, and potentially a value for coordination across policies. Looking at the issue from the viewpoint of a game between "rich and poor" nations, the "North" has grabbed an open access resource-the atmosphere-but lacks the power to exclude the South from it. The real issue is the demarcation of property rights over the atmosphere with the South refusing to accept the Northern land grab. Collectively all countries would benefit from emissions control (although to varying extent) but up till now they have been locked into an unproductive disagreement about who should get most of the atmospheric resource - or conversely who should pay most for abatement. Since it is hardly possible to have a global cap and trade system without solving the issue of allocation of rights between countries, the distributional issue becomes a major impediment for global climate policy.

2015 is not just a special year for the Paris COP, it is also now that we have the full results of the fifth assessment report of the IPCC, summarizing and synthetizing the scientific literature not only on the physics and ecology of climate science but also on economics and social sciences. Chapters 14-16 (Working Group III) contain plenty of new material on policy making at the local, national and international levels - thus covering both the traditional issues of selection and design of policy instruments and the design of climate treaties, IPCC (2014).

As all the many colleagues who have participated know, the IPCC process is quite special and evokes many feelings - frustration and fatigue being the most obvious - but also satisfaction at having collectively reviewed the state of the art for such a broad field. It was to celebrate the termination of these five years of work that I gathered a group of colleagues in Gothenburg, 17-18th October 2014, to the workshop Beyond IPCC-Future Paths for Climate Research ${ }^{1}$ to discuss the IPCC conclusions, and in particular to explore jointly some work we felt was missing and some conclusions particularly concerning future directions of research. Three broad themes permeated much of this meeting: 1. The future of the international climate regime; 2. Damages from climate change and policies for adaptation; 3 . The design of policy instruments including political economy and interaction with stakeholders.

Under the first of these headings we discussed both the future of the IPCC itself and various suggestions for its reform (presentations by Charles Kolstad and by Ottmar Edenhofer) and for the future architecture of international climate negotiations with one paper by Scott Barrett on IPCC future and reform, and another paper by Gunnar Eskeland on the role of leadership in climate negotiations. Concerning the next topic: that of damages from climate change and policies for adaptation, the profession has spent much more time and effort on discounting ${ }^{2}$ which truly is an important and fascinating subject and we had several interesting papers address it (Christian Gollier, Olof Johansson-Stenman, Gernot Wagner, and Ben Groom); but it cannot in principle be more important than understanding the actual numbers for damages. Until the last few years, the literature on damage estimates was excessively thin but now exciting new work is coming in this area and we had at the workshop papers by Kyle Meng and by Eswaran Somanathan as well as one by Michael Hanemann that fits into this new literature with detailed modelling of the economic effects of temperature and other climate parameters, often at a detailed level and finely gridded scale. There was a general feeling that this is an area where considerable new research efforts are needed to really uncover and better understand

1 The economic support from the Swedish Energy Agency and Mistra for this workshop is gratefully acknowledged.

2 We also had interesting papers on uncertainty, partly in relation to modelling and uncertainty by Nicholas Treich (included in this volume) as well as by Mark Freeman, Daniel Johansson and others. 
the ecosystem effects of climate change-not least since there are interactions with many other related issues of global change and other environmental and resource problems that characterize the anthropocene period in history when Man is the dominant force for change on the planet and when we are constantly bumping up against new planetary boundaries (see Rockström et al. 2009; Steffen et al. 2015). There were several papers analyzing the difficulties in building appropriate models to capture damage and analyze mitigation costs as in the IAMs (Integrated Assessment Models), (papers by Per Krusell, Camron Hepburn, Rob Dellink, Karl Steininger, and Nicholas Treich). Clearly more work is needed on both understanding the damage function and on understanding the mechanisms of adaptation that may make the damage easier to cope with.

Turning to the third topic, the literature on various aspects of Policy design is generally rich. The IPCC team did however find one particular type of lacunae. The IPCC is charged with summarizing science in this area and we found ourselves often assuming there would be a large literature when in fact there was none. A key example concerns carbon taxes. This is obviously a central policy and there is a fairly rich set of experiences by now. Some countries like Sweden have a high and fairly general carbon tax (of roughly $125 \$ /$ ton) while most countries have none. Several countries have discussed but been unable to implement even taxes of just 10-20\$/t. Others again (such as most European countries) have fuel taxes which can be seen as sectoral carbon taxes. Clearly it is interesting to understand both the effects of the tax when in place, and the lobbying and other factors that make it difficult to pass the requisite laws that would implement a carbon tax. Ideally we would have wanted articles evaluating the policy experience of the various countries; however, that is not the way articles are structured to get published in economics. There are relatively few case studies and there is very little replication of similar issues from one country study to another, but some papers ${ }^{3}$ at our workshop explored national policy making.

Other areas that have been neglected in the past but are coming en force now are related to feasibility and distributional concerns related to policy (as opposed to pure efficiency issues). Related to this are studies that focus on non-standard aspects of behavior, political economy and lobbying and finally the importance of "positive" (enabling) instruments in the area of technology, research and development, and deployment. In these areas, behavioral issues, leadership and capacity building are very central.

In selecting the papers for this special issue, I have tried to weave together the two threadsone in policy from Copenhagen to Paris and one in research that follows the cycles of the IPCC assessment report. Soon we will be on the other side of both IPCC and COP Paris and the question of what to do next will become particularly poignant. In this light I have tried to select papers that point forward and selected some really fine academic pieces ${ }^{4}$ that make contributions to somewhat broadening the debate thematically, by including papers with a political-institutional or philosophical look at economics, and by introducing voices with a broad geographic sweep - not only the usual US and western Europe perspectives but also some developing country, African, Asian, and Eastern European perspectives.

In the first paper we start by understanding some of the historical determinants of policymaking. The paper Legal Origins and Climate Change Policies in Former Colonies by Fredriksson and Wollscheid (2015) provides a novel explanation for the observed differences in climate change policies across countries: countries' legal origins. The authors investigate whether former colonies have stricter climate policy if their legal origin is British com-

\footnotetext{
3 In particular presentations by Marianne Fay and by Dallas Burtraw.

4 All selected papers in this special issue have gone through a double-blind peer-review process, and I would like to thank all the referees for their excellent and careful work.
} 
mon law or French civil law. Although it may not be self-evident to someone outside the jurisprudence discipline, there are well-founded reasons why we would expect a country's legal origin to play a role for today's climate change policies. For example, French civil law encourages a centralized system where the government directly addresses market failures while the more decentralized common law approach favors contract and private litigation. Fredriksson and Wollscheid list four mechanisms through which countries' legal systems may impact climate change policy. i) French civil law favors government regulation to solve social problems, rather than markets and judicial resolutions of private disputes as emphasized by common law. ii) French civil law has created a more centralized state system which by extension is likely to take transboundary pollution externalities into account to a greater extent. iii) French civil law respects private property to a relatively lesser extent which may create stricter climate policies in circumstances when capital owners are affected. iv) French civil law is viewed by some as less adaptable to new situations, because it relies less on jurisprudence as a source of law. The last implication is ambiguous while the first three would imply that countries with French civil law as their legal system should have created stricter climate policies.

To investigate the relationship empirically, Fredriksson and Wollscheid use a crosssectional dataset of 109 countries. The countries are all non-European former colonies, i.e. countries which have not been in a position to (fully) select their legal framework or history themselves. They find consistent evidence that French civil law countries set stricter climate change policies than common law countries.

In the complex web of questions related to the design of treaties and of the national policies needed to meet the goals in those treaties, there are as mentioned links between policy design and treaty design. One of the areas of major concern is that of carbon leakage: the fear that proactive policy in one country will be undone by increased carbon emissions (and maybe also production, jobs and welfare) in other countries. Burtraw et al. (2015) address these issues in the paper A Proximate Mirror: Greenhouse Gas Rules and Strategic Behavior under the US Clean Air Act which looks at the development of climate policy in the United States in order to draw parallels to the international development of climate change policy. The idea is to coordinate actions to reduce leakage - the same goal that exists on the international level.

To draw a parallel between domestic US policy and international policy, Burtraw et al. looks at the US electricity sector to look for leakage and inefficiencies. The US regulation of the electricity sector is undertaken mainly by the federal Environmental Protection Agency which in August 2015 identified carbon emissions standards and emission rate standards for the electricity sector in each state. It is up to each state to choose its goal-emissions or emission rate-and design policy to reach that goal, be it technology policies, emissions rate averaging, or cap and trade. Burtraw et al. have used this difference in policies among states, which often share the same electricity power market, to look at predatory behaviour and investment in new resources. They examine the coordination problem using a detailed partial equilibrium model of operations and investment and demonstrate that leading jurisdictions have available a rich set of design options including cap and trade with targeted output-based allocation that would impose costs on neighbors and may protect against strategic predation. In the overall context of international negotiations, the authors characterize cooperative game theory as applicable to the search for binding commitments, and non-cooperative game theory as applicable to pledge and review. The first focuses on the stability of coalitions; the second focuses on how coalitions can take shape. Another central message of the paper is that climate policy in large federal countries like the US (and maybe there is relevance also for China and other large countries) is complex. Many of the relevant policy levers are at the disposal not of federal but of state-level decision makers. On top of this is the division of power between 
legislative, executive, and judicial branches of government. The article shows that there are many parallels and thus lessons to be learnt by comparing decision making within the US with decision making on a global scale.

Notwithstanding some important recent improvements in US climate policy, progress towards an environmental treaty and towards sufficiently stringent climate policies in most nations is inexorably slow. This is to a large extent due to the big disparities in interest between various countries when it comes to distributional issues that have already been discussed. One of the few positive signs or hopes for change is actually through the development on new technology (Wagner et al. 2015). As renewables become cheaper, the cost of climate policy and thus the magnitude of the distributional strife will be reduced. We therefore need to put more attention to technology policies. In State-Dependent Enforcement to Foster the Adoption of New Technologies, Coria and Zhang (2015) study policies for technology adoption. As a starting point they take Harrington (1988) who showed that a suitable strategy for regulators to make enforcement more efficient is to target surveillance resources according to past compliance records. Such a scheme generates enforcement leverage as non-compliance triggers greater future scrutiny increasing the expected costs of non-compliance. Coria and Zhang propose an improved transition structure for the audit framework, in which targeting is based not only on firms' past compliance record but also on adoption of environmentally superior technologies. They show that this transition structure would not only foster the adoption of new technology but also increase deterrence by changing the composition of firms in the industry towards an increased fraction of cleaner firms.

In order to have a structured societal conversation concerning climate change we need to build a model and $A$ third wave in the economics of climate change by Teytelboym et al. (2015), concerns the modelling techniques used in economics for climate change. Models frame political and economic discussions in terms of marginal cost benefit analysis and we have become quite reliant on them for decisions on current and future policy. The most frequently used models today are Integrated Assessment Models (IAM) which are built to be sufficiently tractable to cover some of the main issues in a synthetic way but naturally they suffer from many shortcomings. Teytelboym et al. review the shortcomings of the models and go on to examine what other models may constitute an option for future analysis. They first address four main issues that IAM's fail to consider accurately; i) the deep uncertainty in both the relevant physical and economic systems, ii) aggregation and distributional issues where the models still vary enormously in their level of aggregation, iii) technological change and clean innovation and if this should be modelled endogenously or exogenously, iv) the damage function which is important when determining the social costs of climate change and discussion policy options. They then continue to examine some additional shortcomings of the models such as the treatment of equilibrium, absence of the financial system, use of standard discounted expected utilitarianism, and potential for improvement in testing and calibration.

The contribution of the paper is not only bringing the shortcomings of the existing models into light, it also presents a couple of other types of models that may tackle these issues in a better way. These are dynamic stochastic general equilibrium (DSGE) models and agentbased models (ABM) and they may have the potential to perform better. Both types of models have the advantage that they can handle more complex technological dynamics than earlier IAMs and they are also potentially better able to incorporate uncertainty into agent decisionmaking processes. ABMs in particular, while more complex, are much better equipped to model interactions between the agents at their level of aggregation. Economists are already exploring the possibilities and limitations of these newer sorts of models in other areas, such as the financial system, housing markets and technological progress. Results suggest some 
hope concerning these models' potential applicability to better modelling also the economics of climate change. This is greatly needed as there is a demand for improved, more reliable and updated models of climate change.

Ethics is central in climate change economics, and it is commonly incorporated in models through the specification of the social welfare function. ${ }^{5}$ To determine well-being, the utilitarian social welfare function methodology is pervasive in the climate change economics field, although there is considerable disagreement about the parameters of the function itself, including time discounting and treatment of risk. It is apparent that the way in which climate policy depends on empirical facts is a function of the normative framework that the policymaker adopts. In their article Prioritarianism and Climate Change, Adler and Treich (2015) argue that the prevailing approach of using the utilitarian social welfare function as a framework for evaluating climate policy should be re-examined. Here, the authors compare utilitarianism and prioritarianism: the key difference between the two is that prioritarianism conforms to the Pigou-Dalton principle, that is, it is the ethical view that gives greater weight to well-being changes affecting individuals at lower well-being levels.

The authors call for further exploration of the implications of prioritarianism for climate change policies, and prepare the ground by reviewing a range of normative questions that must be addressed in applying the prioritarian framework to the problem of climate change. These broadly fall into one of four groups: measurement of well-being; the degree of social inequality aversion; social choice under risk; and endogenous (variable) population. Finally, they describe some possible implications of the use of the prioritarian framework, with the aim to motivate climate change scholars to consider prioritarianism in the future.

In contrast to the previous theoretical chapter, the following three chapters are more empirical and applied policy analysis. The next two papers use rich datasets from Nepal and Tanzania to investigate clean energy access and agricultural technology adoption respectively. The paper Biogas: Clean Energy Access with Low-Cost Mitigation of Climate Change by Somanathan and Bluffstone (2015) uses data collected in Nepal and looks at the access to biogas and how much fuelwood collection decreases if a household switches from fuelwood to biogas. The rationale to look into fuelwood collection in relation to climate change is because deforestation and forest degradation account for a major share of global annual GHG emissions. Reducing Emissions from Deforestation and Degradation in Developing countries (REDD+) is a still-evolving program envisioned to provide incentives to nonAnnex 1 countries like Nepal to reduce deforestation and forest degradation. Switching from fuelwood to biogas for energy is one way to reduce deforestation and thus the practice would be eligible to receive money from carbon offsets.

Somanathan and Bluffstone use data collected in 2010 and 2011 from nearly 6000 households in the Nepal Living Standards Survey. They estimate the effect of biogas adoption on firewood collection, and they find that the mean reduction in household firewood collection associated with use of a biogas plant for cooking is about $1100 \mathrm{~kg} / \mathrm{year}$ from a mean of $\sim 2400 \mathrm{~kg} /$ year. This estimate is derived comparing only households with and without biogas in the same village, thus effectively removing the influence of many potential confounders. Although relatively large, their central estimate is much smaller than those in the previous literature. However, it is still large enough for the cost of adopting biogas to be heavily subsidized via carbon offsets at a modest carbon price of $\$ 10 / \mathrm{tCO} 2 \mathrm{e}$.

Improving welfare through climate-friendly agriculture: The case of the System of Rice Intensification by Alem et al. (2015), investigates the economic impact of technology

5 See for instance Nordhaus (1994) on the integrated assessment model DICE, or Hope et al. (1993) on the model PAGE. 
adoption on the welfare of rain-dependent small-holder farmers in Tanzania. Climate change will have a major impact on the agricultural sector worldwide and one of the most vulnerable regions to climate change is Sub-Saharan Africa: it is therefore of vital importance we figure out how to create resilient agricultural systems that simultaneously contribute less to climate change. The technology adoption studied is a climate-friendly, but labour demanding, rice farming method known as the system of rice intensification (SRI). SRI reduces water consumption by half, which makes it a promising farming system in the adaptation to climate change in moisture-constrained areas. Furthermore, it does not require flooding of rice fields which decreases emissions of methane- the second major greenhouse gas. Some observers in fact think of SRI as one of the very best options for reducing methane in rice production. Since methane is a short-lived forcer, this may provide some options for affecting the development of global temperatures in a relatively short time period.

Alem et al. use a rich dataset collected in 2013 with 334 households. They look at household yield and total income to determine the difference in welfare among the adopters and nonadopters of SRI. To estimate the outcome and address potential selection bias, the authors use endogenous switching regression which control for unobserved farmer characteristics likely to affect both participation in SRI and the outcome variables of interest. Alem et al. find that SRI is yield enhancing in rain-dependent areas, but its profitability hinges on the actual market price farmers face. SRI becomes profitable only when the rice variety sells at the same market price as that of traditional varieties, but results in loss when SRI rice sells at a lower price. The issue in Tanzania has been that during some periods, the rice variety produced with SRI has been sold at a lower price than the traditional variety. Therefore, Alem et al. argue that the effort of promoting adoption of such types of climate-friendly agricultural practices require complementary institutional reform and support in order to ensure their profitability to small-holder farmers.

In spite of its importance, it is wise to remember that climate change is not our only problem or only priority. Some environmental issues are in fact very closely related to climate changesuch as the local pollution created by burning coal or other fossil fuels. In Quantifying the ancillary benefits of the Representative Concentration Pathways on air quality in Europe, Ščasný et al. (2015) estimate the ancillary benefits of GHG emission reductions in Europe. They estimate the impacts on mortality, morbidity, biodiversity, crop losses, and damages to building materials caused by particulate matter, sulphur and nitrogen emissions that are associated to the burning of fossil fuels. They find that the largest fraction of the ancillary benefits is due to $\mathrm{SO}_{\mathrm{x}}$ and $\mathrm{NO}_{\mathrm{x}}$ emission reductions and the benefits stem mostly from improved human health. The authors also find ancillary benefits in reduced loss of biodiversity and reduced impacts on buildings.

The ancillary benefits of reducing GHG emissions are derived by using data on fossil fuel consumption of power generation from the Integrated Assessment model WITCH. To calculate the ancillary benefits, a reference scenario is used and the authors then derive the difference between the reference scenario and the pollution costs of mitigation. WITCH separates Europe into two large blocs: Western and Eastern Europe. The total values of ancillary benefits for both scenarios are roughly the same with most of the benefits having a domestic origin, that is, the local benefits are enjoyed by residents of the European country in which the abatement of local ambient air pollution occurs. The overall findings are policy relevant since the ancillary benefits are found to be quite substantial and the argument of local benefits from GHG reductions can make carbon taxes more politically acceptable. In spite of this it is clear that attaining a $2{ }^{\circ} \mathrm{C}$ compatible scenario implies a carbon price that is always much higher than what would be justified by local benefits alone and thus we do 
need a way to internalize the global climate externality—which brings us back to the issues of negotiating treaties!

\section{References}

Adler MD, Treich N (2015) Prioritarianism and climate change. Environ Resour Econ (this issue). doi:10. 1007/s10640-015-9960-7

Alem Y, Eggert H, Remidius R (2015) Improving welfare through climate-friendly agriculture: the case of the system of rice intensification. Environ Resour Econ (this issue). doi:10.1007/s10640-015-9962-5

Boyd R, Turner JC, Ward B (2015) Tracking intended nationally determined contributions: What are the implications for greenhouse gas emissions in 2030? Policy paper August 2015. ESRC Centre for Climate Change Economics and Policy, Grantham Research Institute on Climate Change and the Environment

Burtraw D, Palmer K, Paul A, Pan S (2015) A proximate mirror: greenhouse gas rules and strategic behavior under the US clean air act. Environ Resour Econ (this issue). doi:10.1007/s10640-015-9963-4

Coria J, Zhang X-B (2015) State-dependent enforcement to foster the adoption of new technologies. Environ Resour Econ (this issue). doi:10.1007/s10640-015-9943-8

Fredriksson PG, Wollscheid JR (2015) Legal origins and climate change policies in former colonies. Environ Resour Econ (this issue). doi:10.1007/s10640-015-9957-2

Gollier C, Tirole J (2015) Pour un accord efficace sur le climat. TSE, Tolouse

Green J, Sterner T, Wagner G (2014) A balance of 'bottom-up' and 'top-down' in linking climate policies. Nat Clim Change 4:1064-1067

Harrington W (1988) Enforcement leverage when penalties are restricted. J Public Econ 37:29-53

Hope CW, Anderson J, Wenman P (1993) Policy analysis of the greenhouse effect-an application of the PAGE model. Energy Policy 15:328-338

IPCC, Intergovernmental Panel on Climate Change (2014) Ottmar Edenhofer et al., Climate Change 2014: Mitigation. Technical Summary, Cambridge University Press

Nordhaus WD (1994) Managing the global commons: economics of climate change. MIT Press, Cambridge

Nordhaus WD (2013) The climate Casino: risk, uncertainty, and economics for a warming world. Yale University Press, New Haven

Nordhaus W (2015) Climate clubs: overcoming free-riding in international climate policy. Am Econ Rev 105(4):1339-1370

Rockström J, Steffen W, Noone K, Persson Å, Chapin SI, Lambin E, Lenton TM, Scheffer M et al (2009) Planetary boundaries: exploring the safe operating space for humanity. Nature 461:472-475

Ščasný M, Massetti E, Melichar J, Carrara S (2015) Quantifying the ancillary benefits of the representative concentration pathways on air quality in Europe. Environ Resour Econ. doi:10.1007/s10640-015-9969-y

Somanathan E (2009) What do we expect from an international agreement? A perspective from a low-income country. In: Aldy J, Stavins R (eds) Climate change policy beyond Kyoto. Cambridge University Press, Cambridge

Somanathan E (2011) Backloaded policies in the fore. The Environmental Forum, November/December 2011. Environmental Law Institute, Washington, DC

Somanathan E, Bluffstone R (2015) Biogas: clean energy access with low-cost mitigation of climate change. Environ Resour Econ (this issue) doi:10.1007/s10640-015-9961-6

Steffen W et al (2015) Planetary boundaries: guiding human development on a changing planet. Science 347 (6223). doi:10.1126/science.1259855

Teytelboym A, Mealy P, Farmer JD, Hepburn C, Savoie C, Teytelboym A (2015) The third wave in the economics of climate change. Environ Resour Econ (this issue). doi:10.1007/s10640-015-9965-2

Wagner G, Kåberger T, Olai S, Oppenheimer M, Rittenhouse K, Sterner T (2015) Energy policy: Push renewables to spur carbon pricing. Nature 525(7567):27-29

Weitzman M (2014) Can negotiating a uniform carbon price help to internalize the global warming externality? J Assoc Environ Resour Econ 1(1):29-49 